\title{
O QUE É UM MOVIMENTO SOCIAL? REFLEXÕES A PARTIR DA SOCIOLOGIA E SUA ARTICULAÇÃO COM A GEOGRAFIA
}

\author{
WHAT IS A SOCIAL MOVEMENT? REFLECTIONS FROM SOCIOLOGY AND ITS ARTICULATION \\ WITH GEOGRAPHY
}

Daniel Sant'Ana de SOUSA ${ }^{1}$

Ensaio recebido em 15/08/2018 e aceito em 17/12/2018

Palavras-chave: Movimentos Sociais; Contexto de

Produção; Espaço.

Keywords: Social Movements; Production Context; Space.

\section{INTRODUÇÃo}

O que é movimento social? Para responder a esta complexa questão propõe-se uma reflexão ancorada em autores que são referência na temática, como Gohn (2011) e Melucci (1989), e, mesmo assim, a resposta muda dependendo do contexto de sua produção, pois preconizar uma conceituação

\footnotetext{
1 Doutorando em Geografia pelo Programa de Pós-graduação em Geografia na Universidade do Estado do Rio de Janeiro (PPGEO - UERJ). E-mail: danielgeouerj@gmail.com.
}

\begin{abstract}
A B S T R A C T
The present essay reflects on the difficulty of constructing a definition on the theme of social movements. Understanding that agents will have different interests depending on each place, the production of the concept will depend on its context of production. The objective is to analyze how the authors present in Sociology and Geography present what is social movement and, thus, to expose that it is not possible to construct a normative answer or, from the idea exposed by Ribeiro (2001), as a "seal of quality "about the concept. Methodologically, the essay uses theoretical sources from the bibliographic analysis of authors such as Gohn (2011), Ribeiro (2001), Souza (2006) and Melucci (1989). The main result is that there is a common point in the ideas among all authors, that of contextualize the concept of social movements, which allows to understand their possible variations that attend to specific and dynamic particularities in space and time.
\end{abstract}


sobre o que é movimento social dependerá de uma análise que considere sua variação em diferentes contextos ao longo do espaço e tempo.

Desta forma, o objetivo deste ensaio é refletir sobre como os autores Melucci (1989), Gohn (2011), Ribeiro (2001) e Souza $(2006,2013)$ abordam o que é movimento social e, assim, expor que não é possível construir uma resposta normativa ou, a partir da ideia exposta por Ribeiro (2001), um "selo de qualidade" a respeito do conceito. Para alcançar tal objetivo utiliza-se como recurso metodológico uma análise bibliográfica com base na temática dos movimentos sociais, tendo como foco a construção inicial de uma reflexão embasada em autores da sociologia e, posteriormente, como seus pensamentos impactam e são impactados pela Geografia.

0 ensaio, assim, divide-se em três etapas. A primeira consiste em uma análise a partir das ideias de Gohn (2011) com o objetivo de perceber a importância de se localizar geograficamente o conceito sobre movimentos sociais e entender o contexto de sua produção, o que mostra o impacto de uma visão espacial que influencia outras ciências.

A segunda parte utiliza-se das ideias contidas em Melucci (1989), uma referência internacional quando se trata de movimentos sociais. $\mathrm{O}$ autor pondera que haverá uma diferença dos movimentos antes e depois do período pós-industrial. Isso já marca a sua responsabilidade em considerar diferentes tempos e como isso impacta diretamente na produção do espaço, bem como a eclosão de novos agentes e sujeitos com necessidades distintas.

E a terceira parte propõe uma articulação das ideias contidas na Sociologia e Geografia. Tendo como base Ribeiro (2001), que dialoga diretamente com a Geografia, e Souza $(2006,2013)$, pretendese analisar como cada autor desenvolve o que é um movimento social, de modo a evidenciar que os significados atribuídos ao conceito trabalhado estariam conectados ao seu contexto de produção, causando um desconforto ao pesquisador, pois não se encontra uma resposta baseada em uma racionalidade normativa.

Para definir o que é movimentos sociais é necessária uma construção baseada em diferentes autores, bem como compreender o contexto particular de produção da pesquisa, seus agentes, relações de poder e seus impactos, em múltiplas escalas, no espaço.

\section{O USO DE UM CRITÉRIO GEOGRÁFICO-ESPACIAL COMO UM RECURSO PEDAGÓGICO}

E para iniciar este trabalho, insere-se no debate a socióloga Maria da Glória Gohn (2011), uma referência da área, e seu livro "Teorias dos Movimentos Sociais: Paradigmas clássicos e contemporâneos"2", com sua primeira edição publicada em 1997. 0 objetivo de utilizar a autora é

\footnotetext{
2 Informações contidas na capa do próprio livro: Doutora em Ciência Política Pela USP, com pós-doutorado em Sociologia pela New School University/Nova Iorque, é professora titular da Unicamp, Pesquisadora I do CNPq e Secretária Executiva do Research Committee "Social Movements and Social Classes", da Associação Internacional de Sociologia.
} 
apresentar como uma conceituação normativa de movimentos sociais é complexa, obrigando até mesmo o autor mais cartesiano, que não é o caso dela, a refletir sobre como os significados atribuídos ao termo estariam conectadas ao seu contexto de produção. Para iniciar o debate proposto, apresentase a primeira das cinco "grandes" questões que motivaram Gohn a escrever seu trabalho:

(...) apesar do interesse dos cientistas sociais, e da ocorrência de ciclos efetivos de boom de diferentes movimentos sociais, cinco grandes questões permaneceram na produção acadêmica, como lacunas ou como problemas não resolvidos, embora tenham estado presentes na literatura e alimentado grande parte do debate a seu respeito. Elas são: 1.0 próprio conceito de movimentos sociais: afinal, o que são esses movimentos? (GOHN, 2011, p. 11, grifos nossos).

Existe em Gohn (2011) a mesma preocupação, ao apresentar sua primeira grande questão, com a pergunta proposta na introdução deste trabalho, já indicando uma necessidade de reflexão em torno do conceito. Assim, a autora identifica a ocorrência de ciclos e diferenças na abordagem dos movimentos sociais, destacando a importância de sistematizar a ideia dos autores, o lugar e a conjuntura3 ${ }^{3}$. A própria Gohn (2011) expõe isso a partir de seus objetivos:

\begin{abstract}
Após mais de duas décadas de estudos e pesquisas sobre a temática/problemática dos movimentos sociais, elaboramos este livro com quatro objetivos básicos. Primeiro: sistematizar as principais teorias e os paradigmas correspondentes sobre os movimentos sociais na produção das ciências sociais contemporânea. Segundo: realizar um estudo comparativo entre estas teorias apresentando suas diferenças, semelhanças e o debate que elas têm desenvolvido entre si. Terceiro: caracterizar as linhas gerais do paradigma explicativo que tem sido utilizado para o estudo dos movimentos sociais na América Latina, apresentando algumas inadequações no uso das teorias correntes, a partir da caracterização dos cenários sociopolíticos e econômicos das lutas sociais latino-americanas. Quarto: Delinear algumas tendências que estão sendo construídas ao redor da temática/problemática dos movimentos sociais no Brasil a partir de transformações ocasionadas pela globalização da economia, da política (e dos Estados-nações) e das relações socioculturais em geral (Ibidem, p. 11).
\end{abstract}

Para entender a aplicação dos movimentos sociais na particularidade brasileira, bem como identificar transformações ocasionadas pela globalização da economia, Gohn (2011) apresenta as principais ideias, autores e particularidades dos movimentos a partir da visão do paradigma norteamericano, europeu e latino-americano.

O importante aqui é ressaltar como a ideia do que é movimento social obriga os autores que escrevem sobre o assunto a sair de uma "zona de conforto". Não há uma resposta normativa e baseada em uma conceituação de difícil refutação (dentro do que se espera em uma lógica moderna do conhecimento científico). Impõe ao autor pensar que seu lugar de produção expõe a particularidade do conceito, sendo necessária sua localização no espaço e tempo. A partir do momento que o pesquisador não considera os contextos históricos, as necessidades particulares de cada sociedade e seu espaço de produção, a aplicação do conceito ao um determinado fenômeno ou processo pode levar à imprecisões.

\footnotetext{
${ }^{3}$ Levo em consideração que a autora tem como objetivo identificar o espaço e tempo do conceito.
} 
Gohn (2011) apresenta uma síntese da produção brasileira sobre movimentos sociais nas décadas de 1980-1990 e expõe que não há uma definição normativa. Destaca-se o caso do terceiro ponto, onde a autora apresenta o resultado de se utilizar teoricamente ideias constituídas no paradigma europeu e a tentativa de aplicar na realidade brasileira.

Primeiro - uma grande vitalidade de estudos de natureza mais empírico-descritiva, centradas nas falas dos agentes. Embora pouco analíticos eles conferiram às ciências sociais no Brasil grande dinamismo e renovação. Segundo - uma certa divisão dos estudos nas áreas acadêmicas e a localização da maioria deles nos programas de pósgraduação no país. Assim, a antropologia estudou os movimentos indígenas; a política, a sociologia urbana e o planejamento urbana pesquisaram sobre movimentos sociais populares; o direito e a arquitetura acompanharam as questões ligadas à terra e à moradia etc. Terceiro - a utilização teórica do paradigma europeu, em suas várias vertentes, para a análise dos dados da realidade. 0 resultado por um lado, foi a utilização acrítica de teorias elaboradas no exterior para a análise dos movimentos sociais no Brasil, e na América Latina, muitas vezes incorporando categorias que se opõem no debate teórico; por outro lado, o quase completo silêncio sobre o paradigma norte-americano, assim como o seu debate com os europeus, nos anos 80 . Destaque-se ainda a ínfima importância dada nestes debates à produção e à própria existência dos movimentos na América Latina e no chamado "Terceiro Mundo" (Ibidem, p. 10).

Ao se utilizar teorias de fora sem um conteúdo crítico de reflexão nos anos de 1980, impacta em uma análise equivocada da realidade no Brasil sobre a discussão dos movimentos sociais. E mais, de acordo com a própria Gohn, essa postura praticamente esconde a América Latina do debate, em um período de grande eclosão desses movimentos, principalmente no Brasil, pois em 1980 há uma reabertura democrática na política brasileira.

Além disso, Gohn (2011) ainda chama a atenção para a subdivisão dos paradigmas e a forma de apresentação da organização do seu livro, onde expõe que:

o uso de um critério geográfico-espacial foi um recurso pedagógico utilizado não para definir o paradigma em si mas apenas para localizá-lo diferencialmente, enquanto corrente teórico-metodológica composta por teorias formuladas a partir de realidades específicas. A América do Norte, a Europa e a América Latina possuem contextos históricos específicos, e lutas e movimentos sociais correspondentes a eles (Ibidem, p. 10, grifos nossos).

Desta forma, a partir da análise baseada em Gohn (2011), percebe-se que a autora se preocupa em utilizar um critério geográfico-espacial para localizar o conceito diferencialmente a partir de realidades específicas. Assume que existe uma complexidade de se conceituar o que é movimentos sociais, obrigando a autora a pelo menos ponderar, mesmo não sendo geógrafa, o que Livingstone (1995) denomina de "virada espacial" (spatial turn), onde os pesquisadores passam a considerar o espacial na produção de seus próprios trabalhos4.

\footnotetext{
4 Para o Livingstone, o ocidente priorizava o tempo e a história em detrimento do espaço e da geografia, indo ao passado para reafirmar o presente e, por vezes, sem considerar que cada lugar não consegue ser explicado sem suas particularidades. Para saber mais leia o trabalho de LIVINGSTONE, D. (1995) The Spaces of Knowledge: Contribuitions towards a historical geografphy of science. Environment and Planning D: Society and Space, 13, 5 - 34.
} 
Se, ao considerar de maneira incipiente uma conceituação de movimentos sociais própria para esta pesquisa, levar em consideração que movimentos são formados a partir da indignação de um grupo social perante questões diversas, mas elencadas notadamente em três vertentes - econômicas, políticas e culturais - onde as relações de poder entre os diferentes agentes se apresentam de forma desigual, as necessidades de cada grupo se ajustam aos diferentes períodos históricos, bem como as carências específicas de cada lugar.

Desta forma, ao expor a complexidade de responder o que é movimento social e entender que existem variações do conceito conectados ao seu contexto de produção, para dar continuidade a este trabalho, propõe-se uma discussão a respeito do conceito a partir da visão de Alberto Melucci com o objetivo de aprofundar a discussão.

\section{ALBERTO MELUCCI E AS CONTRADIÇÕES DO MUNDO CONTEMPORÂNEO}

As necessidades dos movimentos sociais são as mesmas que na década de 40 e 50 ? Se voltam contra quem, o Estado? Qual o papel do processo de globalização na análise dos movimentos atuais? E como entender todos esses contextos no seu processo de produção? Alberto Melucci, de quem Gohn utiliza como citação em seus trabalhos, é um autor reconhecido internacionalmente sobre a temática dos movimentos sociais e apresenta uma reflexão para as perguntas acima elencadas. Para ele, novas contrações emergem no mundo contemporâneo, onde as necessidades ultrapassam as reivindicações ligadas ao espaço urbano e melhores condições de trabalho.

Melucci (1989) aborda que ao longo da década de 1980 o desenvolvimento capitalista não pode ser assegurado pelo simples controle da força de trabalho e pela transformação dos recursos naturais para o mercado,

Requer uma intervenção crescente nas relações sociais, nos sistemas simbólicos, na identidade individual e nas necessidades. As sociedades complexas não têm mais uma base "econômica", elas produzem por uma integração crescente das estruturas econômicas, políticas e culturais. Os bens "materiais" são produzidos e consumidos com a mediação dos gigantescos sistemas informacionais e simbólicos (Ibidem, p. 58).

Neste caso, os conflitos sociais transcendem o tradicional sistema econômico-industrial para as áreas culturais, em que afeta a identidade, o tempo e o espaço na vida cotidiana, a motivação e os padrões culturais da ação individual. Novas contradições emergem e a visão do pesquisador deve acompanhar o dinamismo das relações sociais no mundo contemporâneo.

Então, o que é um movimento social? Para Melucci (1989):

Os movimentos sociais são difíceis de definir conceitualmente e há várias abordagens que são difíceis de comparar. Os vários autores tentam isolar alguns aspectos empíricos dos fenômenos coletivos, mas como cada autor acentua elementos diferentes, dificilmente se pode comparar definições. Infelizmente, estas são mais definições empíricas dos conceitos analíticos. (Ibidem, p. 54, grifos nossos). 
Ora, o fragmento de texto com a visão de Melucci corrobora com o que se trabalhou em Gohn no subcapítulo anterior. Cada autor acentua elementos diferentes o que torna difícil de comparar, pois cada movimento social terá uma necessidade, uma marca em seu tempo e espaço, um contexto, e que impactará, sem dúvida, na produção do conceito. Sendo assim, mais fácil do que comparar o conceito contido no pensamento de cada autor, é necessária uma reflexão de como cada um constrói sua teoria sobre o que é um movimento social.

Desta forma, de acordo com o Melucci (1989), como saber se existe um movimento atrás do protesto ativo? A palavra movimento torna-se sinônimo de tudo que muda na sociedade, e por vezes esconde o verdadeiro significado de cada ação coletiva, em que o limita a uma generalização empírica, ou seja:

Estas proposições evidenciam a mesma falta de distinção entre uma generalização empírica e uma definição analítica. Como diferenciar entre um tumulto antigovernamental de bêbados, uma greve sindical e uma ampla mobilização contra a política nuclear? Todos eles podem ser empiricamente considerados como protestos, mas cada um deles tem um significado e uma orientação significativamente diferentes. A definição de protesto como um comportamento disruptivo demonstra as impropriedades das generalizações empíricas. Tal definição implica um sistema de referência, um conjunto de limites ou fronteiras que são rompidas. De fato, aqueles que escrevem sobre o protesto fazem implicitamente referência ao sistema político. 0 único sistema possível de referência torna-se o confronto com as autoridades e ação coletiva é simplesmente reduzida à ação política. Esta sobrecarga política, como já se destacou, é analiticamente sem base, particularmente quando referida aos movimentos contemporâneos (Ibidem, p. 55-56).

Sendo assim, Melucci (1989) trabalha movimento social como uma forma de ação coletiva que depende de seu sistema de referência e se suas dimensões analíticas, pois o mesmo comportamento empírico pode ser visto de maneira distintas, como refere-se ou não a um sistema organizacional, a um sistema político, a um modo de produção.

Assim, o autor deixa claro que existem particularidades e que há a necessidade de levar em consideração os diferentes contextos, bem como a eclosão de movimentos que transcendem a vertente política para análise.

Para definir analiticamente um movimento social, Melucci (1989) utiliza três categorias: o conflito, a solidariedade e o rompimento dos limites do sistema como dimensões analíticas básicas.

Defino conflito como uma relação entre atores opostos, lutando pelos mesmo recursos aos quais ambos dão um valor. A solidariedade é a capacidade de os atores partilharem uma identidade coletiva (isto é, a capacidade de reconhecer e ser reconhecido como uma parte da mesma unidade social). Os limites de um sistema indicam o espectro de variações tolerado sua estrutura existente. Um rompimento destes limites empurra um sistema para além do espectro aceitável de variações. Eu defino analiticamente um movimento social como uma forma de ação coletiva (a) baseada na solidariedade, (b) desenvolvendo um conflito, (c) rompendo os limites do sistema em que ocorre a ação. (Ibidem, p.57).

Assim, o que é um movimento social? Para Melucci desenvolver sua resposta comparou sua análise com a proposição de Tarrow, além de refletir que existem variáveis que não permitem um 
entendimento normativo sobre o conceito. Gohn e Melucci desenvolvem suas ideias levando em consideração um contexto e um dinamismo que impacta diretamente nas necessidades de cada sociedade. Há uma preocupação espacial no contexto de produção do conceito de movimento social da parte do autor quando expõe que o que Tarrow produziu abarca necessidades de sociedades pósindustriais, sendo, provavelmente, diferente se levar em consideração países em outros estágios de desenvolvimento.

Ainda, de acordo com Melucci, há a possibilidade de que movimentos sociais sejam separados dos outros fenômenos coletivos, como delinquência e reivindicações organizadas, que são empiricamente associados com movimentos e protestos. Neste caso, expõe-se a pluralidade de elementos e a necessidade de distingui-los para buscar uma reflexão que aborde o resultado de uma dada ação coletiva. Existe a imprescindibilidade de expor variáveis que possam enriquecer a análise dos movimentos sociais, até porque, de acordo com o autor, estes não podem ser encarados como um sinônimo de tudo que muda na sociedade, e nem colocados empiricamente de forma rígida para a análise.

\section{GEOGRAFIA E MOVIMENTOS SOCIAIS}

Melucci, como abordado anteriormente, constrói seu raciocínio que define movimento sociais como uma forma de ação coletiva (a) baseada na solidariedade, (b) desenvolvendo um conflito, (c) rompendo os limites do sistema em que ocorre a ação. Contudo, como os autores brasileiros, influenciados ou não pelo pensamento de Melucci, desenvolvem suas discussões sobre o que é um movimento social?

Ana Clara Torres Ribeiro 5 é uma importante pesquisadora quando o assunto é movimentos sociais. A autora, assim como Gohn e Melucci, admite a dificuldade existente de se trabalhar o conceito, mais especificamente, no Brasil. De um lado há a "emergência de novas práticas e mediadores que realizam a produção do conhecimento sem apoio sistemático das ciências sociais". E de outro, uma predominância de "leituras abrangentes da conjuntura econômica e política" que afirmam a crise dos movimentos sociais em decorrência da dissolução do "mundo do trabalho" ou pré-concebem a totalidade dos "sentidos da ação", vinculando-se a uma reivindicação por cidadania ou luta contra o neoliberalismo (2001, p. 9).

Ao comparar a construção sobre o que é movimento social em Melucci, Ribeiro (2001) acrescenta um fato novo. Existe o problema de valorizar a ação social, que está distante do discurso dos atores e do sentimento que originam a ação, ou seja, diversas formas de protestos, organizações e

\footnotetext{
${ }^{5}$ Embora doutora em sociologia possui grande afinidade com a geografia.
} 
reivindicações explodem e não são interpretadas, o que pode abrir uma lacuna que será preenchida com formulações e representações difundidas pelos os governantes e a imprensa.

De fato, não há consenso com relação ao conceito de movimento, já que coexistem diferentes e competitivas culturas políticas e, logo, expectativas de transformação das relações sociais. Por esta razão, e outras associáveis à crise paradigmática das ciências sociais e do denominado socialismo real, não se dispõe de uma teoria plenamente formulada e aceita que permita distinguir, com relativa tranquilidade, entre, por exemplo, protesto e movimento; reivindicação e movimento; grupo de pressão e movimento; instituição (associações de moradores, partidos e sindicatos de movimento (Ibidem, p. 10).

Assim, Ribeiro (2001) demonstra que não está preocupada em definir um conceito de movimentos sociais de forma normativa, se preocupa em abordar que há obstáculos na dimensão política e teórica, onde difunde-se novas crenças políticas a partir de meados dos anos 1980 e com maior força nos anos 1990.

Para o geógrafo Marcelo Lopes de Souza (2016) as conjunturas no Brasil impactam na articulação de ações coletivas. Em seu trabalho disserta que de 1970 até metade dos anos de 1980 ascende os chamados "novos movimentos". No Brasil, a "abertura política" proporciona a eclosão de protestos, o que impacta em uma (re) constituição da mobilização social de favelas e periferias de bairros de classe média.

A partir da segunda metade dos anos de 1980 o sentimento de crise se instala, assim como já havia colocado o pensamento de Ribeiro (2001), no qual Souza (2006) se baseia, que pesquisadores universitários se desinteressam pelo tema dos ativismos. Focam na análise de políticas públicas e dos canais participativos estatais, trocando a reflexão sobre as práticas sociais pelo exame dos formatos organizativos. E nos anos 1990 em diante o sentimento de crise é substituído pelo "estado de coma", pois:

As organizações dos ativismos, quando não definham, entram em colapso e retrocedem a uma espécie de miserável "vida vegetativa" (...), começando a tentar mimetizar o "formato ONG" (...) ou a escorar-se em articulações com o Estado e em canais participativos oficiais para tentar sobreviver. 0 que se segue é uma grande onda de cooptação: a perspectiva de "ser governo" ou de participar de uma parceria com o Estado no âmbito de institucionalidades como conselhos gestores e orçamentos participativos acaba colaborando para o "desarmamento" e a domesticação de muitas organizações de ativismos. Ao mesmo tempo em que, na cena tradicional do ativismo de bairro, se notam um desencanto e uma fadiga, misturados com um otimismo em face da emergência de novas institucionalidade participativas formais (...), "novas radicalidades" emergem. Atores sociais procuram, congregados em torno de barricadas como o enfrentamento da segregação, do racismo e da escassez de moradias, exercer um protagonismo: sobressaem, aí, o hip-hop e o movimento dos sem-teto, que se expandem desde os anos 90 no brasil. Eles fazem os "novos ativismos" dos anos 70 e 80 parecerem, então, um tanto "velhos" (SOUZA, 2006, p. 282).

Existe uma parcela de intelectuais que banalizam o tema ou não o creditam a devida profundidade. Ribeiro (2001, p. 11) sugere a busca por se valorizar tanto o sujeito, "na plenitude da 
sua voz, emoção e gesto, quanto o reconhecimento das condições materiais e político-institucionais de sua manifestação no espaço público". Além de uma "reunião das condições objetivas às condições subjetivas da ação social". O objetivo é não aceitar qualquer ação coletiva como movimento social, assim como Melucci aborda, mas também não colocar parâmetros rígidos como se existisse "um selo de qualidade". 0 ideal é que cada pesquisador entenda as particularidades e conjunturas espaciais e temporais para a construção da análise.

Assim, "a ideia de movimento social parte de alguns princípios - que soa simultaneamente analíticos, políticos e éticos - e do registro de numerosas práticas sociais" RIBEIRO (2001, p. 12). Para a autora os movimentos eclodem de práticas que, ao se atualizarem ou contradizerem determinantes da vida coletiva, transformam o tecido social. Não se deve destacar somente as mobilizações a partir de uma vertente economicista, pois as motivações podem integrar a dimensão política, cultural e a vida cotidiana.

Os sujeitos complexos também emergem e conseguem ir além da carência inicial que motiva o protesto. Eclodem reivindicações de valores culturais e políticos, como o Movimento Sem Terra que é contra a produção de transgênicos e articula a luta pela terra, revelando o que pode ser chamado de movimentos de múltiplas reivindicações. Depreende-se, assim, que as oportunidades são desvendadas ao decorrer e no cotidiano dos movimentos.

Souza (2006) já evidencia um raciocínio mais incisivo ${ }^{6}$ sobre o que pode ser considerado ativismo, ação coletiva e movimentos sociais:

\begin{abstract}
Os ativismos sociais são um conjunto mais amplo de ações públicas organizadas, do qual os movimentos sociais seriam um subconjunto. Os ativismos, como ações públicas organizadas e relativamente duradouras, diferenciam-se de ações coletivas efêmeras e pouco organizadas ou desorganizadas, como quebra-quebras, saques e outras; e, como ações públicas, em sentido forte, diferenciam-se tanto da criminalidade ordinária e de organizações terroristas, quanto de grupos de pressão e lobbies em sentido restrito, que tendem a atuar nos "corredores do poder estatal", pressionando parlamentares ou administradores públicos e articulando tráfico de influência, entre outras atividades que não propriamente públicas. Os movimentos sociais, de sua parte, seriam uma modalidade especialmente crítica e ambiciosa de ativismo social, distinta de ativismo paroquiais. Estes encaminham reivindicações pontuais, sem articulá-las com questionamentos mais profundos, relativos a problemas nacionais e internacionais, e sem construir pontes entre a conjuntura, cujo domínio não ultrapassam, e as estruturas, que não chegam a tematizar (SOUZA 278, p. 278)".
\end{abstract}

Para Souza $(2006,2013)$ os movimentos sociais fazem parte de um conjunto mais amplo referente aos ativismos sociais, que se mostra conveniente reservar a expressão movimento social para designar ativismo críticos em relação ao status quo. 0 autor faz essa ressalva pois não entende, assim como Ribeiro (2001), qualquer ação coletiva como movimento social, embora que para o desenvolvimento de seu trabalho seja necessário delimitar o que cada dimensão representa.

\footnotetext{
${ }^{6}$ Indica uma postura mais normativa, mas necessária em sua construção de raciocínio para diferenciar o que são movimentos sociais.
} 
Para este trabalho a sistematização proposta por Souza é de suma importância para que não exista uma banalização do que é um movimento social. Mesmo que pareça a elaboração de uma ideia mais rígida, neste caso, não há como fugir de uma tentativa de classificação. Embora não exista um "selo de qualidade" do conceito, além de identificar o contexto que está inserido o espaço e tempo do movimento social, é necessário refletir se não é uma ação coletiva, algo meramente adaptativo que não ataca o status quo. Considera-se, assim, que Souza entende o contexto, bem como suas particularidades na produção do conceito.

\section{PARA NÃO CONCLUIR}

As sociedades complexas, de acordo com Melucci (1989), pós-industriais, não apresentam mais espaço para uma visão redutora a partir de movimentos de base política ou econômica. Ribeiro (2001) aborda que não é necessária uma análise rígida, pela busca de um parâmetro pautado em um selo de qualidade, o que é ou não um movimento social. É necessário dotar o pesquisador de ferramentas para que ele possa observar a dinâmica dos movimentos sociais transcendo uma visão engessada do passado, mas sem uma banalização do que seria um movimento social. Souza $(2006,2013)$ já aborda a necessidade de uma sistematização do que é um movimento social a partir de uma construção sofisticada.

Um ponto em comum entre todos os autores, inclusive Gohn (2011), é a tentativa de localizar e contextualizar o conceito de movimentos sociais, o que permite entender suas possíveis variações que atendem a particularidades específicas e dinâmicas no espaço e tempo.

Os significados atribuídos ao conceito trabalhado estariam conectados ao seu contexto de produção, ocasionando uma busca para entender a sua situação e posição ao longo da ciência, pois o próprio conceito tira o pesquisador de uma "zona de conforto" ancorada em uma suposta racionalidade normativa.

Percebe-se, assim, que existem outras racionalidades alternativas, e não uma única racionalidade de conceituação dos movimentos sociais, como o que em sociedades industriais estavam ligadas as vertentes política ou a econômica. Aliás, pode-se dizer que as diferentes vertentes - política, econômica e cultural - podem e devem se entrelaçar, o impossibilita uma análise normativa a respeito dos movimentos sociais e permite que o pesquisador expanda sua visão a respeito dos atores envolvidos, bem como os conflitos existentes na produção do espaço.

\section{REFERÊNCIAS}

GOHN, Maria da Glória. Teoria dos Movimentos Sociais: Paradigmas Clássicos e Contemporâneos. 9a edição. São Paulo: Loyola, 2011.
MELUCCI, Alberto. Um objetivo para os movimentos sociais? Tradução Suely Bastos. Revista Lua Nova. São Paulo, № 17, JUNHO 89. 
RIBEIR0, Ana Clara Torres Ribeiro. Leituras de Movimentos: conjuntura, ação e poder. Revista Temporalis, Ano 2, n.4, p. 9-19, (JUL/ DEZ) 2001. SOUZA, Marcelo José Lopes de. A prisão e a ágora: reflexões em torno da democratização do planejamento e da gestão das cidades. 1a edição. Rio de Janeiro: Bertrand Brasil, 2006.

SOUZA, Marcelo José Lopes de. Os conceitos fundamentais da pesquisa sócio-espacial. 1 a edição. Rio de Janeiro: Editora Bertrand, 2013. 